\title{
Circulation of Immunosuppressive Viruses and Avian Encephalomyelitis Virus in Backyard Chicken Flocks
}

\author{
Priscila de Castro Almeida1, Pricila Ribeiro Silva Borges², Priscilla K. Koerich1, \\ Roberta Torres de Melo $^{3 *}$, Igor Alves Batista ${ }^{2}$, Eliane Pereira Mendonça4, \\ Rogério Reis Silva ${ }^{3}$, Lillian Karla Silva ${ }^{3}$, Belchiolina Beatriz Fonseca ${ }^{3}$ \\ ${ }^{1}$ Elanco Saúde Animal, São Paulo, Brazil \\ ${ }^{2}$ BRF S/A, Uberlândia, Brazil \\ ${ }^{3}$ Faculdade de Medicina Veterinária da Universidade Federal de Uberlândia, Uberlândia, Brazil \\ ${ }^{4}$ Faculdade de Medicina Veterinária da Universidade de Uberaba, Uberaba, Brazil \\ Email: *roberta-melo@hotmail.com
}

How to cite this paper: Almeida, P.C., Borges, P.R.S., Koerich, P.K., Melo, R.T., Batista, I.A., Mendonça, E.P., Silva, R.R., Silva, L.K. and Fonseca, B.B. (2020) Circulation of Immunosuppressive Viruses and Avian Encephalomyelitis Virus in Backyard Chicken Flocks. Advances in Microbiology, 10, 203-213.

https://doi.org/10.4236/aim.2020.105016

Received: November 29, 2019

Accepted: May 3, 2020

Published: May 6, 2020

Copyright $\odot 2020$ by author(s) and Scientific Research Publishing Inc. This work is licensed under the Creative Commons Attribution International License (CC BY 4.0).

http://creativecommons.org/licenses/by/4.0/ (c) (i) Open Access

\begin{abstract}
The objective of this study was to evaluate the circulation of Chicken Anemia Virus (CAV), Infectious Bursal Disease Virus (IBDV), Avian Reovirus (ARV) and Avian Encephalomyelitis virus (AEV) in properties of backyard chickens and carry out an epidemiological analysis. We evaluated 200 samples of chickens from 19 backyard chicken property. Only one property (P10) did not present serological titers for the diseases evaluated. This property is close to industrial farms as well as the other properties, however, P10 remained a few years without the breeding of chicks and these were the first poultry to be housed on site. This reinforces the importance of the fallow period for poultry production. The prevalence of virus-seroreactive birds was $78 \%(156 / 200)$, $64.5 \%$ (129/200), 78\% (156/200), 78\% (156/200) for CAV, IBDV, ARV and, EA, respectively. All the free-range farms studied are within a radius of 500 meters to $6 \mathrm{Km}$ away from some establishments of industrial poultry. There was a correlation between serological titers for CAV and the frequency of disease in poultry $(\mathrm{r}=0.6178)$. In places where birds are frequently sick, $30.76 \%$ reported that the disease occurs in chicks, $30.76 \%$ in broilers, $23.07 \%$ in broiler chickens and $7.69 \%$ in birds of all ages. Birds get sick more often in the summer period. The owners reported that the most common signs of disease were respiratory signs (snoring and nasal discharge) (46.15\%), diarrhea $(30.76 \%)$, and paralysis of wings and/or paws (38.46\%). There was a correlation between the presence of untreated water in the property and serological titers for ARV $(r=0.5576)$. This report draws attention not only to high serological prevalence for the viruses studied but also important epidemio-
\end{abstract}


logical aspects of backyard chicken diseases that may indirectly influence the industrial production.

\section{Keywords}

Chicken Anemia Virus, Infectious Bursal Disease Virus, Avian Reovirus, Epidemiology

\section{Introduction}

Brazil is recognized worldwide for its excellence in industrial poultry farming, highlighting its technology in management, standardization in production respecting animal welfare, traceability and biosecurity. These characteristics are associated with industrial production although the practice of poor creation technology is a reality relevant to the country.

The creation of backyard chickens has been widely exploited over the years by small producers. Many of these breeding farms do not have specialized consulting to obtain adequate management yet; and due to the lack of information on basic biosecurity, they have low sanitary status and may result in the emergence of diseases. Properties with low sanitary status represent a risk for industrial poultry farming, mainly where there is intense exploitation of poultry such as in the south and southeast regions of the Brazil.

Immunosuppressive diseases are of great importance in poultry production. These make them susceptible to various other illnesses, which include zoonotic diseases, especially those transmitted by food such as salmonellosis and campylobacteriosis. Some of these diseases are difficult to control, at the same time they can cause economic losses, due to the drop in production, and a high rate of morbidity and mortality [1]. Among the most important viruses that affect the immune system of poultry, we can describe Chicken Anemia Virus (CAV), Infectious Bursal Disease Virus (IBDV), and Avian Reovirus (ARV). These viruses cause chicken infectious anemia (CIA), infectious bursal disease (IBD) and avian reoviruses (REO) respectively.

Caused by a DNA virus, from the Circoviridae family, CIA is evidenced by transient anemia, growth retardation, thymus hypoplasia, and other signs [2]. The IBD is caused by an RNA virus and can be present in the clinical or subclinical form [3]. Sudden or high mortality and drop in production are determinant factors of the economic impact of this disease. The Avian Reovirus (ARV) belongs to the genus Orthoreovirus, family Reoviridae being the disease commonly associated with other pathogens. Affecting the gastrointestinal tract, respiratory system, and skeletal tissue, REO mainly affects young birds [4]. Another disease of high relevance is avian encephalomyelitis (AE) caused by the Avian Encephalomyelitis virus (AEV). Infected breeding in the posture period transmits the disease via vertical, and the chicks will present nervous signs such as ataxia, tre- 
mors, paralysis, and death in a few days [5] [6] [7]. All the diseases presented here are resistant to the environment [8] [9] [10] [11].

Since the mentioned diseases are extremely relevant to poultry production, monitoring and control must be continuous. Also, despite the importance of the viruses that cause these diseases in industrial poultry, little is known about their interference in backyard chicken production. Thus, the objective of this study was to evaluate the prevalence of the CAV, IBDV, ARV and AEV in properties of backyard chickens and carry out an epidemiological analysis between the serological titles, clinical disease and some biosecurity factors.

\section{Material and Methods}

Blood samples from 200 backyard chickens aged between 12 and 56 weeks were collected in 19 free-range farms in the city of Uberlândia-MG, from March to October 2018. All free-range farms have a deficient veterinary technical assistance. Although the techniques used in this work are the routine of poultry production, the research was submitted to the CEUA (Ethics Committee on the Use of Animals) of the Federal University of Uberlândia under the number of $036 / 18$.

From the free-range farms visited, only four were previously vaccinated, following: P5: Fowlpox Virus (FV), Infectious Bronchitis Virus (IBV), New Castle Disease (NCD) and IBDV; P9: FV, NCD; P17: NCD, FV, Marek's Disease (MD), Infeccious Coryza (IC), IBV, IBDV; P19: FV, NCD; MD, IC and IBV.

Blood samples were obtained by puncture of the blood through the ulnar vein, with sterile and disposable needles and syringes, and stored in tubes for vacuum collection with clot activator, properly identified. These samples were stored in isothermal boxes until arrival at the laboratory of Molecular Epidemiology of the Faculty of Veterinary Medicine (FAMEV) of Uberlândia Federal University (UFU), where all blood serums were pipetting and individual tips and then forwarded to the Animal Health Laboratory for serological analysis. The method for identifying infected chicken was used a commercial ELISA indirect developed by IDEXX laboratories as indicated by the manufacturer. The antigen was placed in plaque for sensitization. After sensitization, the plates were washed and serum was then added and incubated at $18^{\circ} \mathrm{C}-26^{\circ} \mathrm{C}$ for 30 minutes. Serum was then washed and placed along with an enzyme substrate for incubation followed by washing and adding the enzyme substrate for incubation for 15 minutes at $18^{\circ} \mathrm{C}-26^{\circ} \mathrm{C}$. The reaction was then interrupted by adding the Interruption Solution. The test was read based on the results obtained in the spectrophotometer by optical density and absorbance values. The calculations of the titles were automatically provided software (IDEXX). Serum samples with titrations greater than 396 should be considered positive and indicate vaccination or other exposure to IBDV, ARV and AEV. For CAV this value is 1000.

The free-range farms were evaluated as some points related to biosecurity and to the clinical signs of diseases. These were mapped relating proximity to the 
industrial farms of the region using Google Maps. For statistical analysis, the Kolmogorov-Smirnov test was used to verify whether the data were parametric for further analysis of the differences between averages by ANOVA. The correlation test performed was Pearson's test. A significance level of 0.05 was considered and the Graph Pad Prism 7.0 program was used.

\section{Results}

\section{Serologic titers evaluated}

From the free range farms visited, there was previous vaccination in the properties P5 and P19 for IBDV. The farmers were not able to inform whether the same birds evaluated in this study had been vaccinated for the mentioned diseases. However, in these country farms there was a vaccination approximately 6 and 12 months before to the collection. The mean serologic titers of the evaluated country farms for the diseases that affect the immune system and AE are described in Figure 1.

According the manufacturer's guidance of the ELISA, title values above 397 are considered seropositive for IBDV, AEV and ARV and above 1000 are considered seropositive for CAV. Thus, when assessing the population mean, it is possible to notice that the properties $\mathrm{P} 5, \mathrm{P} 10$ and P14 were those that did not react to ARV; P8, P10, P15, P16, P18 did not react to IBDV; P10 did not react to AEV and CAV. The country farms P3, P14 and P15 were the most reacted to CAV; P8 and P12 for ARV; P14 and P19 for IBDV and P6 and P8 for AEV. The $\mathrm{P} 10$ was the only one that was not reagent for any of the viruses evaluated.

In addition to the evaluation of the mean serological titers, the histograms were constructed to better evaluate the serological titers in the free-range farms. For this, the titles were divided into categories exactly as recommended by the manufacturer. A histogram of serologic titer for CAV, IBDV, ARV, and EAV can be visualized in Figures 2(a)-(d) respectively.

The guidance of the ELISA recommends that the titration values from 1 are considered positive for all the evaluated agents. Thus, a high number of reagent birds can be observed for the virus investigated. The number of birds that did not react was $22 \%$ (44/200), 35.5\% (71/200), $21 \%(42 / 200)$, and $21 \%(42 / 200)$ birds for CAV, IBDV, ARV, and AEV respectively. Thus, the prevalence of reagent birds for the virus was 78\% (156/200), 64.5\% (129/200), 79\% (158/200), $79 \%(158 / 200)$ for CAV, IBDV, ARV, and AEV, respectively. From the country farms analyzed in $94.73 \%$ (18/19), at least one (1) bird was positive for CAV, 94.73\% (1/19) for EA, 73.68\% (14/19) for IBDV and 84.21\% (16/19) for ARV.

The mapping of the studied free-range farms showed the large concentration of industrial farms around. All the free-range farms studied are within a radius of 500 meters to $6 \mathrm{Km}$ away from some establishments of industrial poultry activities (Figure 3).

The farm P10 was better evaluated for the understanding of the lowest serological titles. The birds of this farm are considered improved chicken bought 
from a company specializing in the production of backyard chicken. This farm is close to industrial farms as well as other. The P10 is $3.5 \mathrm{Km}$ from a laying farm, $5.5 \mathrm{Km}$ from a broiler farm, and $5.8 \mathrm{Km}$ from a breeding broiler farm in addition to the proximity to other backyard farms (1.5 to $1.8 \mathrm{Km}$ from P2 and P12) (Figure 3). However, these free-range farms remained a few years without the breeding of birds, and these were the first birds to be housed on-site. The birds evaluated in this way had similar ages (approximately 16 months of age).

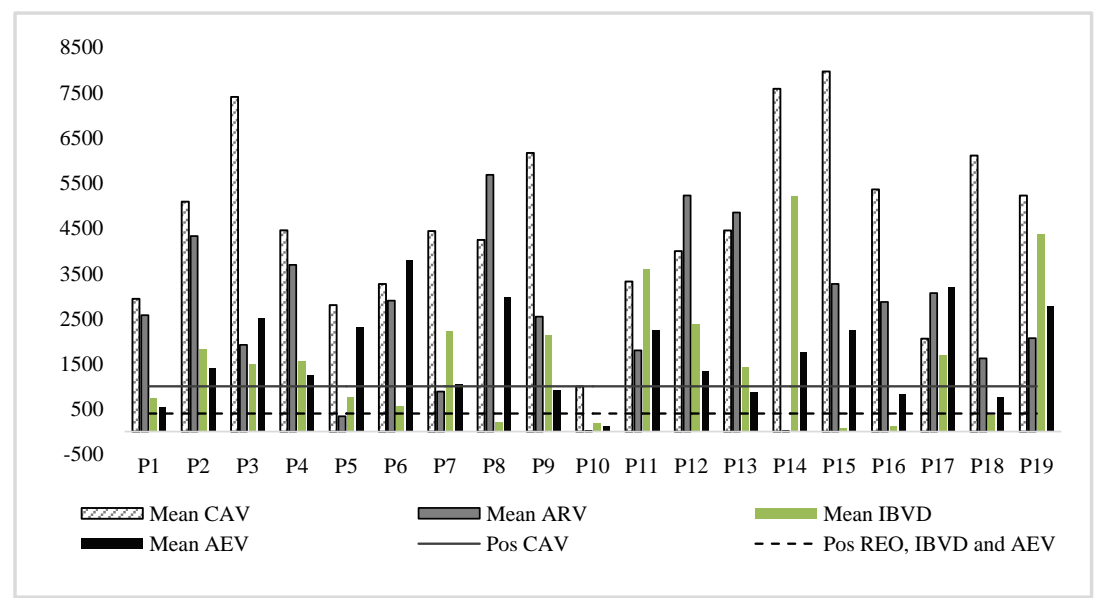

Figure 1. Mean Serologic titers of the properties evaluated for IBDV, CAV, ARV and AEV. A high coefficient of variation was observed for the title of all diseases evaluated, and for AEV ranged from $35.96 \%$ to $105.87 \%$; CAV from $14.28 \%$ to $110.38 \%$; ARV from $35.81 \%$ to $86.47 \%$ and IBDV from $40.54 \%$ to $121.89 \%$.

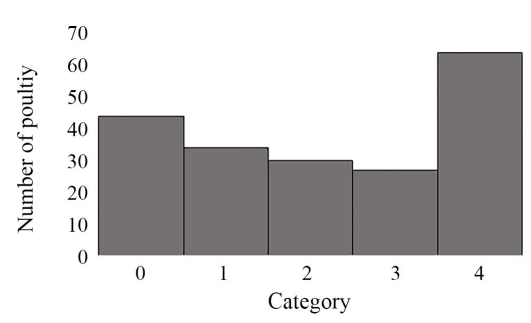

(a)

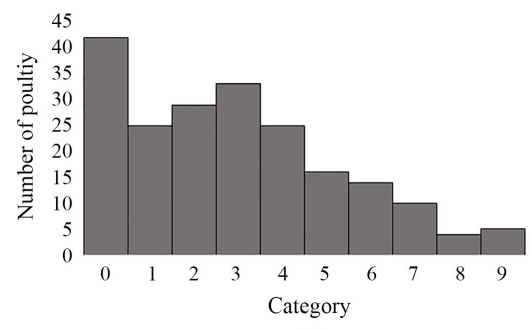

(c)

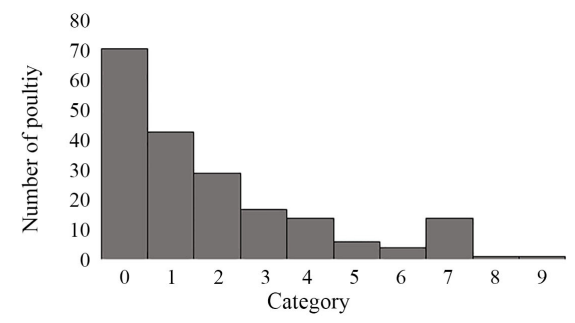

(b)

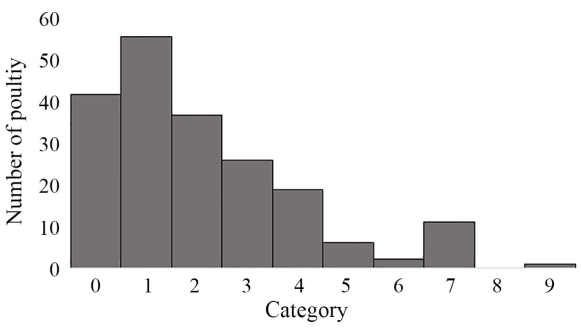

(d)

Figure 2. Distribution of titles in categories for CAV, IBDV, ARV and AEV. ${ }^{\star}$ The categories were divided as follows for IBDV, ARV and AV: 0: Titles from 0 to 396 (considered negative). From category 1 titles are considered positive: Category 1: Titles of $397-1000$, 2: Titles from 1001 to 2460, 3: Titles from 2460 to 3000, 4: Titles from 3001 to 4000, 5: Titles from 4001 to 5000 and so on. For CAV: 0: Titles 0 to 999 (considered negative). From category 1 the headings are considered positive: Category 1: Titles of 1000 - 2460, 2: Titles from 2461 to 5050, 3: Titles from 5051 to 8660, 4: Titles above 8661 . 


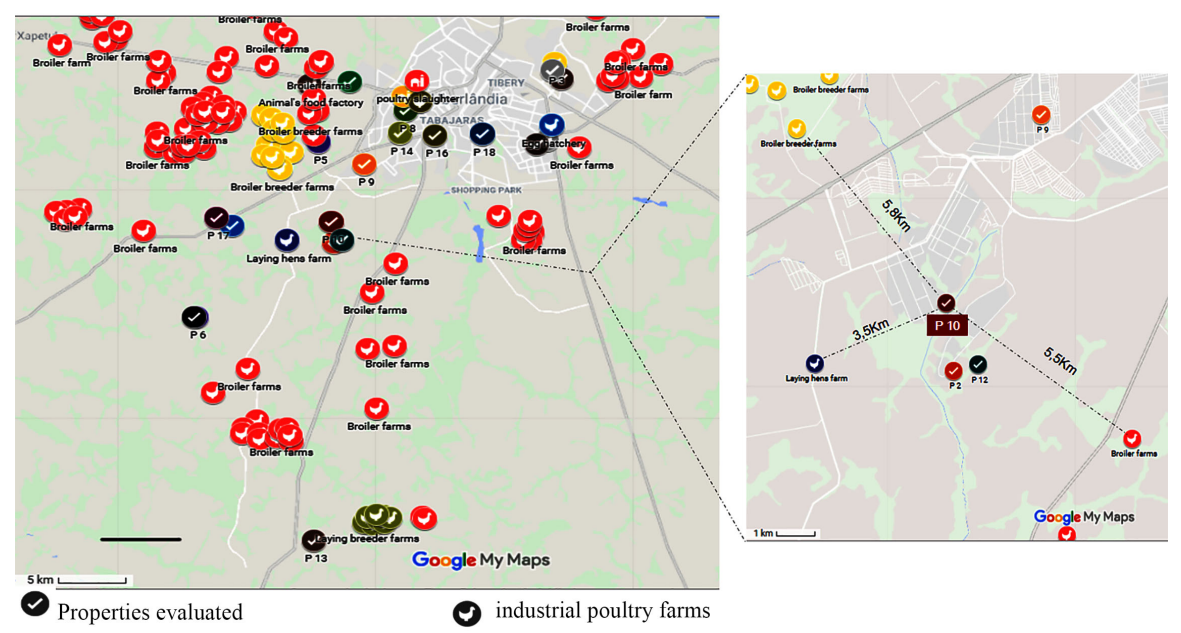

Figure 3. Location of the country farms evaluated and proximity to industrial broiler farms, commercial laying hens and broiler breeder farms. The close up in the figure shows the distance between the P10 property and commercial farms.

\section{Disease evaluates and serological titers}

Table 1 presents the correlation test between the serological titers for the evaluated viruses and the evaluated variables.

A total of $68.42 \%(13 / 19)$ farms answered that poultry often get sick and there was a correlation between serological titers for $\mathrm{CAV}$ and the frequency of disease in poultry $(\mathrm{r}=0.6178)$. In places where birds are frequently sick, a total of $30.76 \%(4 / 13)$ reported that the disease occurs in older animals, $30.76 \%$ in broilers (4/13), $23.07 \%$ in chicks and $7.69 \%$ in animals of all ages. When the farmers were asked about the time of year that most of the birds get sick $69.23 \%(9 / 13)$ answered that the diseases occur in the summertime, $15.38 \%(2 / 13)$ in the wintertime and $15.38 \%(2 / 13)$ in both periods. The owners reported that birds became sick with respiratory signs (snoring and nasal discharge) $(46.15 \%(6 / 13))$, diarrhea $(30.76 \%(4 / 13))$ and paralysis of wings and/or paws $(38.46 \%(5 / 13))$, with signs can be observed at the same time or not. It is important to report that during our visits, the main clinical symptoms observed were those related to the respiratory tract (mucus in the nostrils, swollen head and tearing). There was a correlation between the presence of untreated water in the property and serological titers for ARV $(r=0.5576)$.

There was no correlation between serological titles and characteristics of the farm, multispecies breeding, and cleaning of facilities. In free-range farms where there were multispecies breeding the most common birds were hens, ducks, and geese.

\section{Discussion}

In Brazil, the epidemiological status of backyard chickens is poorly studied and the prevalence of antibodies to IBDV, CAV, AEV, and ARV is not well known. In the present study, IBDV presented a prevalence of $64.5 \%$ and $78 \%$ for CAV, 
Table 1. Correlation between the serological titers for the evaluated viruses and biosecurity items or frequency of diseases in birds.

\begin{tabular}{ccccc}
\hline & CAV & IBDV & ARV & AEV \\
\hline How often birds get sick $(\mathrm{p} ; \mathrm{r})$ & $0.0048 ;$ & $0.3637 ;$ & $0.088 ;$ & $0.4398 ;$ \\
& 0.6178 & -0.2208 & 0.401 & 01884 \\
Characteristic of the farm $(\mathrm{p} ; \mathrm{r})$ & 0.5863 & 0.2764 & 0.9378 & 0.8376 \\
& -0.1333 & -0.2631 & -00.192 & -0.05042 \\
Multispecies $(\mathrm{p} ; \mathrm{r})$ & 0.2682 & 0.2964 & 0.3084 & 0.6268 \\
& -0.2675 & -0.2528 & 0.2468 & 0.1192 \\
Cleaning and Desinfection & & & \\
& 0.6324 & 0.7908 & 0.1731 & 0.4851 \\
Untreated water $(\mathrm{p} ; \mathrm{r})$ & -0.1706 & 0.06522 & -0.326 & 0.0652 \\
& 0.4568 & 0.2681 & 0.0131 & 0.5530 \\
& -0.184 & -0.2676 & 0.5576 & 0.1452 \\
\hline
\end{tabular}

${ }^{*}$ Poultry often got sick-answered by the owner and/or observed during the visit. Characteristic of the farm: extensive or semi intensive. ${ }^{\star *}$ All facilities were rated as reasonable or poor cleaning condition.

AEV or ARV. Titles values for IBDV were also high in backyard chicken in Rio Grande do Sul (80.2\%) [12] and Slovenia (78\%) [13]. The serological prevalence for ARV was $21.6 \%$ in Rio Grande do Sul [12], 41\% in Nigeria [14] and 92\% in Slovenia [13]. The values found for AEV ranged from 57.1\% in Sudan [15], 65\% in Galapagos Island [16] and $82.23 \%$ in Lower Paraguaçu-Bahia [17]. It is not common to find report results of serological prevalence of CAV in backyard chicken.

Although some researches mention the high prevalence of virus evaluated in backyard chickens, it is not common to find reports of clinical disease in these poultry. As discussed by Barrios et al. [18], backyard chicken, in natural challenge selection, seems to be more resistant to clinical disease caused by CAV than industrial poultry. The Serological prevalence reported in our study indicates that the virus is circulating but leads to hypothesize that the pathogen, host and environment relationship can be determinant in the manifestation of these diseases in backyard poultry. It is probable that the low-density breeding with free access will determine the non-occurrence of the clinical disease when compared to industrial birds.

The fact that most of the analyzed free-range farms had at least one positive bird for the agents studied (CAV (94.73\%), AEV (94.73\%), ARV (84.21\%) and IBDV (73.68\%) illustrates the permanence or periodic circulation of these pathogens in these backyard productions. The high frequency of farms with seroconvertion of poultry indicates a risk of introduction of agents that are distributed in nature in poultry commercial farms. However, it should also be considered that the region where the backyard production is located in this study is a site of the rich production of breeding broiler that is widely immunized with live vaccines for IBDV, AEV and CAV. In this way, the possibility of transmission of the vaccine strains from industrial birds to backyard chicken should be considered.

Several reports reinforce that the presence of immunosuppressive agents fa- 
vors the establishment of pathogenic microorganisms of importance also for public health. Sheela et al. (2003) observed that birds infected with CAV had depressed immune responses, especially the mucosal immune responses in co-infection with Salmonella Enteritidis. According to McNamee et al. [19], there is an association between CAV and IBDV inoculation and increased $S$. aureus capacity to induce chondronecrosis in poultry cartilage and to favor the development of septic arthritis and osteomyelitis in humans. BDV infection exacerbated colonization and shedding of $C$. jejuni in poultry [20], so IBDV control can also indirectly benefit the intestinal health of chickens.

When evaluating the serological prevalence of the free-range farms (ARV, IBDV, AEV, and CAV) only the P5 and P17, reported the vaccination for IBDV, and the P9 and P19 presented reports of vaccination, but for other diseases. The results of IBDV titers for the vaccinated birds are within the positivity line for the disease. Antibody titers of a virus challenge in the field tend to be higher than vaccines titers. For this, it is necessary to establish a timeline for the evaluation of the levels of antibodies of the evaluated diseases, during different stages of the life of the birds. Property P17 presented higher average titers than the P5 property, but without evaluation of the historical titles it is not possible to affirm that vaccination or challenge-to-field titles. What can be verified, however, is that the vaccinated properties presented titers similar or even lower than other properties without reports of vaccination, for example P2, P7, P9, P12, P14, P19.

It was verified the high density of industrial breeder broilers in the proximities with the country farms of this study (Figure 3 ). This proximity brings to light the importance of the possibility of dissemination of the virus studied as well as the change of these viruses over time.

Studies show that ARV, CAV, AEV and IBDV are resistant to environmental conditions and disinfection [8] [9] [10] [11]. However, the long downtime of the free-range farms P10 showed low serological titers for all the diseases evaluated. This shows the importance of fallowing to reduce the pressure of infection even related to viruses of difficult control as those researched in this report.

Lack of vaccination, stress due to coexistence with other birds, and dirty environment are predisposing factors to viral, bacterial or fungal infectious diseases [21]. However, in this study, we have not found a correlation between the cleaning conditions of the facilities. We should consider here a possible bias about our results since no property presented good classification for cleaning conditions.

Although the importance of multispecies creation for the increase of diseases is recognized, in this study, the presence of poultry of different species on the same property has not interfered with serological titers. For most of the diseases evaluated in this work, the natural host is the chicken, and perhaps, for this reason, the correlation between multispecies creation and the high serological title was not found. However, the presence of multispecies of birds in the same property can be considered an alert because of the possibility of mutation and genetic 
recombination of the agents facilitated by the interspecies dissemination.

In the correlation study, CAV showed a correlation with the parameter "poultry get sick frequently" with $r=0.6178$. According Mukaka [22], a value of $r$ between 0.5 and 0.7 indicates a moderate correlation. Farmers indicated for us that clinical signs were prevalent among young birds (chicks $23.07 \%$ and broilers-30.76\%); hot period of the year (summer-69.23\%) and associated with symptoms of snoring and nasal secretion (46.15\%) followed by paralysis of wings and legs $(38.46 \%)$ and diarrhea (30.46\%). The present signs reported by the farmers are not indicative of either CAV or other diseases evaluated in this study.

The CIA is a disease of young birds, characterized by marked anemia, bone marrow hypotrophy, increased mortality, reduced weight gain, and generalized atrophy of lymphoid organs [23]. Beside this, disorders caused by CAV induce immunodepression [2] [24] [25], which increased susceptibility to other infections [26]. When we visited the farms, we observed that the main clinical symptoms were those related to the respiratory tract (mucus in the nostrils, swollen head and tearing). Prezotto et al. [26] verified synergic pathological effects of $\mathrm{CAV}$ and a respiratory microorganism (Mycoplasma gallispticum). Older birds are susceptible to viral replication but do not develop clinical signs [27]. Farmers reported that the disease occurs at the same ages that CAV is described-chicks and young chicken. Admittedly, it is important to mention, that our analysis may contain bias as poultry may have fallen ill at a different moment from the presence of serological titers. Thus, it is possible that the birds became ill due to IBDV, AEV or ARV before our serological analysis. However, we do not have this accurate information.

The summertime was reported as the most critical for disease manifestation. In the region where poultry is raised, summer is a period associated with rain, where high temperature and humidity can favor the spread of numerous pathogens.

The presence of ARV titers in the present study showed a correlation with untreated water, probably explained to be a virus resistant to environmental conditions and disinfection [10].

\section{Conclusion}

This report draws attention not only to high serological prevalence for the viruses studied but also to epidemiological aspects important for diseases in backyard chicken who may indirectly influence birds in industrial production. The report reinforces that even in countryside areas the period of downtime decreases the infection pressure and also shows that the presence of CAV in the properties may predispose to other clinical diseases in birds. Surveillance for the virus assessed in this study should be constant in backyard chicken production since the proximity to industrial poultry production may lead to cross-contamination which may result in the appearance of strains with genetic alterations in the future. 


\section{Conflicts of Interest}

The authors declare no conflicts of interest regarding the publication of this paper.

\section{References}

[1] Zhang, Y., Cui, N., Han, N., Wu, J., Cui, Z. and Su, S. (2017) Depression of Vaccinal Immunity to Marek's Disease by Infection with Chicken Infectious Anemia Virus. Frontiers in Microbiology, 8, 1863. https://doi.org/10.3389/fmicb.2017.01863

[2] Adair, B.M. (2000) Immunopathogenesis of Chicken Anemia Virus Infection. Developmental \& Comparative Immunology, 24, 247-255.

https://doi.org/10.1016/S0145-305X(99)00076-2

[3] Mundt, E. and Müller, H. (1995) Complete Nucleotide Sequences of 59 and 39 Non-Coding Regions of Both Segments of Different Strains of Infectious Bursal Disease Virus. Virology, 209, 10-18. https://doi.org/10.1006/viro.1995.1226

[4] Davis, J.F., Kulkarni, A. and Fletcher, O. (2013) Reovirus Infections in Young Broiler Chickens. Avian Diseases, 57, 321-325. https://doi.org/10.1637/10515-021313-Case.1

[5] Hoekstra, J. (1964) Experiments with Avian Encephalomyelitis. British Veterinary Journal, 120, 322-335. https://doi.org/10.1016/S0007-1935(17)41704-0

[6] Calnek, B.W., Taylor, P.J. and Sevoian, M. (1960) Studies on Avian Encephalomyelitis. IV. Epizootiology. Avian Disease, 4, 325-347.

https://doi.org/10.2307/1587684

[7] Rocha, P.M.C., Barros, M.E.G, Rocha, B.P., Souza, F.A.L., Mendonça, F.S. and Evêncio-Neto, J. (2019) Severe Outbreak of Avian Encephalomyelitis in Laying Hens in Northeastern Brazil. Brazilian Journal of Poultry Science, 2, 1-4. https://doi.org/10.1590/1806-9061-2018-0749

[8] Yuasa, N. (1992) Effect of Chemicals on the Infectivity of Chicken Anaemia Virus. Avian Pathology, 21, 315-319. https://doi.org/10.1080/03079459208418846

[9] Mandeville, W.F.I, Cook, F.K. and Jackwood, D.J. (2000) Heat Lability of Five Strains of Infectious Bursal Disease Virus. Poultry Science, 79, 838-842. https://doi.org/10.1093/ps/79.6.838

[10] Jones, R.C. (2000) Avian Reovirus Infections. Revue Scientifique et technique office international des epizooties, 19, 614-625. https://doi.org/10.20506/rst.19.2.1237

[11] Hoerr, F.J. (2010) Clinical Aspects of Immunosuppression in Poultry. Avian Disease, 54, 2-15. https://doi.org/10.1637/8909-043009-Review.1

[12] Santos, H.F.L, Lovato, L.T., Flôres, M.L., Trevisol, I.M., Mazzutti, K.C. and Pan, K.A. (2008) Anticorpos contra vírus em galinhas de terreiro do Estado do Rio Grande do Sul, Brasil. Ciência Rural, 38, 7. https://doi.org/10.1590/S0103-84782008000700020

[13] Volk, M. (2005) Health Status of Backyard Flocks in Slovenia-Some Preliminary Data. Institute for Poultry Health, 11, 47.

[14] Owoade, A.A., Ducatez, M.F. and Muller, C.P. (2006) Seroprevalence of Avian Influenza Virus, Infectious Bronchitis Virus, Reovirus, Avian Pneumovirus, Infectious Laryngotracheitis Virus and Avian Leukosis Virus in Nigerian Poultry. Avian Diseases, 50, 222-227. https://doi.org/10.1637/7412-071505R.1

[15] Zahraa, F.A., Lutfi, O.H. and Kheir, S.A.M. (2010) Case Report: Anti-Avian Encephalomyelitis Virus Antibodies in Layer Flocks in Khartoum State. The Sudan 
Journal of Veterinary Research, 25, 59-64.

[16] Deem, S.L., Cruz, M.B., Higashiguchi, J.M. and Parker, P.J. (2011) Diseases of Poultry and Endemic Birds in Galapagos: Implications for the Reintroduction of Native Species. Animal Conservation, 15, 73-82. https://doi.org/10.1111/j.1469-1795.2011.00489.x

[17] Cruz, R.P.C., Santos, T.C., Cruz, A.V.C, Santos, C.A.C., Silva, E.N., Ramos, I., Costa, N.P. and Fernandez, L.M.B. (2015) Investigação soroepidemiológica da encefalomielite aviária em criatórios avícolas de subsistência no pólo avícola do baixo $\mathrm{Pa}$ raguaçu-Bahia. Revista de Educação Continuada em Medicina Veterinária e Zootecnia do $C R M V$-SP, 12, 68-68.

[18] Barrios, P.R., Marín, S.Y., Resende, M., Rios, R.L., Resende, J.S., Horta, R.S., Costa, M.P. and Martins, N.R.S. (2009) Occurrence of Chicken Anemia Virus in Backyard Chickens of the Metropolitan Region of Belo Horizonte, Minas Gerais. Revista Brazileira de Ciências Avícolas, 11, 2. https://doi.org/10.1590/S1516-635X2009000200010

[19] McNamee, P.T., McCullagh, J.J., Rodgers, J.D., Thorp, B.H., Ball, H.J., Connor, T.J., McConaghy, D. and Smyth, J.A. (1999) Development of an Experimental Model of Bacterial Chondronecrosis with Osteomyelitis in Broilers Following Exposure to Staphlococcus aureus by Aerosol, and Inoculation with Chicken Anemia and Infectious Bursal Disease Viruses. Avian Pathology, 28, 26-35. https://doi.org/10.1080/03079459995019

[20] Subler, K.A., Mickael, C.S. and Jackwood, D.J. (2006) Infectious Bursal Disease Virus-Induced Immunosuppression Exacerbates Campylobacter jejuni Colonization and Shedding in Chickens. Avian Diseases, 50, 179-184. https://doi.org/10.1637/7434-090705R.1

[21] Borne, P. (2003) Vacinas e vacinação na produçao avícola. Gessuli Guias, Porto Feliz, $140 \mathrm{p}$.

[22] Mukaka, M.M. (2012) Statistics Corner: A Guide to Appropriate Use of Correlation Coefficient in Medical Research. Malawi Medical Journal, 24, 69-71.

[23] Tongkamsai, S., Lee, M.S., Cheng, M.C., Chaung, H.C., Tsai, Y.L. and Lien, Y.Y. (2019) Persistent Infection with Chicken Anemia Virus in 3-Week-Old Chickens Induced by Inoculation of the Virus by the Natural Route. Pathogens, 8, 48. https://doi.org/10.3390/pathogens8020048

[24] Jeurissen, S.H., Janse, M.E., Van Roozelaar, D.J., Koch, G. and De Boer, G.F. (1992) Susceptibility of Thymocytes for Infection by Chicken Anemia Virus Is Related to Pre- and Posthatching Development. Developmental \& Comparative Immunology, 2, 123-129. https://doi.org/10.1155/1992/52484

[25] Miller, M.M. and Schat, K.A. (2004) Chicken Infectious Anemia Virus: An Example of the Ultimate Host-Parasite Relationship. Avian Diseases, 48, 734-745.

https://doi.org/10.1637/7271-090304R

[26] Prezotto, C.F., Marin, S.Y., Araújo, T.S., Barbosa, F.O., Barrios, P.R., Gomes, A.M., Peconick, A.P., Resende, M. and Sousa, R.V. (2016) Experimental Coinfection of Chicken Anemia Virus and Mycoplasma gallisepticum Vaccine Strains in Broiler Chicks. Brazilian Journal of Poultry Science, 18, 475-480.

https://doi.org/10.1590/1806-9061-2016-0235

[27] Smyth, J.A., Moffett, D.A., Connor, T.J. and McNulty, M.S. (2006) Chicken Anaemia Virus Inoculated by the Oral Route Causes Lymphocyte Depletion in the Thymus in 3-Week-Old and 6-Week-Old Chickens. Avian Pathology, 35, 254-259. https://doi.org/10.1080/03079450600717349 